Int. J. Dev. Biol. 57: 873-883 (2013)

doi: $10.1387 / \mathrm{ijdb} .120240 \mathrm{hs}$

\title{
The expression and function of thymosin beta 10 in tooth germ development
}

\author{
MAHO SHIOTSUKA $1,2, \#$, HIROKO WADA ${ }^{1, \#,}$, TAMOTSU KIYOSHIMA $^{1, \#,}$, KENGO NAGATA ${ }^{1}$, \\ HIROAKI FUJIWARA ${ }^{1}$, MAKIKO KIHARA ${ }^{1,2}$, KANA HASEGAWA ${ }^{1,3}$, HIROTAKA SOMEYA ${ }^{1,4}$, \\ ICHIRO TAKAHASHI ${ }^{2}$ and HIDETAKA SAKAl ${ }^{1, *}$ \\ ${ }^{1}$ Laboratory of Oral Pathology, ${ }^{2}$ Department of Orthodontics, ${ }^{3}$ Department of Endodontology and Operative Dentistry and
${ }^{4}$ Department of Removable Prosthodontics, Faculty of Dental Science, Kyushu University, Fukuoka, Japan
}

ABSTRACT This study presents the expression pattern and functions of thymosin beta 10 (T $\beta 10)$,

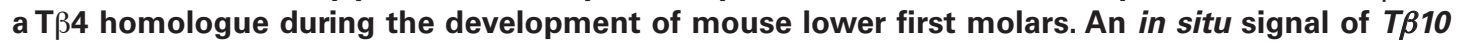
was detected on embryonic day 10.5 (E10.5)-E15.5 mainly in dental mesenchymal cells as well as in dental epithelial cells, while $T \beta 4$ was expressed in dental epithelial cells. In the late bell stage, preodontoblasts with strong $T \beta 10$ expression and preameloblasts with strong $T \beta 4$ expression exhibited face-to-face localization, suggesting that an intimate cell-cell interaction might exist between preodontoblasts and preameloblasts to form dentin and enamel matrices. A strong $T \beta 10$ signal was found in odontoblasts in the lateral side of the dental pulp and in Hertwig's epithelial root sheath, thus suggesting that T $\beta 10$ participates in the formation of the outline of the tooth root. An inhibition assay using TR10-siRNA in E11.0 mandibles showed significant growth inhibition in the tooth germ. The T $\beta 10$-siRNA-treated E15.0 tooth germ also showed significant developmental arrest. The number of Ki67-positive cells significantly decreased in the T $\beta 10$-siRNA-treated mandibles. The cellular proliferative activity was also significantly suppressed in T $\beta 10$-siRNA-treated cultured mouse dental pulpal and epithelial cells. These results indicate that developmental arrest of the tooth germ might be caused by a reduction in cell proliferative activity. The stage-specific temporal and spatial expression pattern of $T \beta 10$ in the developing tooth germ is indicative of multiple functions of $T \beta 10$ in the developmental course from initiation to root formation of the tooth germ.

KEY WORDS: thymosin beta 10, thymosin beta 4, tooth germ, development, knockdown assay

\section{Introduction}

Mammalian tooth development is mediated through sequential and reciprocal epithelial-mesenchymal interactions similar to those observed in other organs, e.g. the hair, glands, lungs, kidneys, etc. A complex multi-step process of gene expression is involved in the early stage of tooth development (Pispa et al., 2003). Tooth germ development occurs via coordinated multistep molecular interactions between the ectomesenchymal and ectodermal cells (Thesleff 2003). Tooth germ development also occurs via coordinated multi-step molecular interactions between endomesodermal and ectodermal cells (Mina 2001). There are many reports regarding the expression of various genes related to tooth morphogenesis (Cobourne and Sharpe 2003; Thesleff
2003; Chen et al., 2009). However, the precise molecular signaling pathways related to the initiation, growth and differentiation of the tooth germ have not yet been fully elucidated.

Previous studies have demonstrated that thymosin beta 4 (T $\beta 4$ ) is closely involved in the tooth germ development of the mouse lower first molar (Akhter et al., 2005; Ookuma et al., 2013). $\mathrm{T} \beta 10$, a $\mathrm{T} \beta 4$ homologue, showed a quite different expression pattern in the tooth germ on embryonic day 15.5 (E15.5). An

Abbreviations used in this paper: DE, dental epithelium; DM, dental mesenchyme; DP, dental papilla; E, embryonic day; EO, enamel organ; HERS, Hertwig's epithelial root sheath; GAPDH, glyceraldehyde-3-phosphate dehydrogenase; P, postnatal day; SM, surrounding mesenchyme; T $\beta 4$, thymosin beta 4 ; $\mathrm{T} \beta 10$, thymosin beta 10; TUNEL, terminal deoxynucleotidyl transferase-dUTP nick end labeling.

*Address correspondence to: Hidetaka Sakai. Laboratory of Oral Pathology, Faculty of Dental Science, Kyushu University, 3-1-1 Maidashi, Higashi-ku, Fukuoka 812-8582, Japan. Tel: +81-92-642-6325. Fax: +81-92-642-6329. E-mail: hsakaiop@ dent.kyushu-u.ac.jp

\# Note: The indicated authors have contributed equally to this paper.

Supplementary Material (two figures) for this paper is available at: http://dx.doi.org/10.1387/ijdb.120240hs 
intense expression of $T \beta 10$ was observed in the dental papilla, while the expression of $T \beta 4$ was localized in the odontogenic epithelial cells (Akhter et al., 2005), thus suggesting different functional roles for $T \beta 10$ and $T \beta 4$ in the developmental course of the tooth germ. Although both $\mathrm{T} \beta 10$ and $\mathrm{T} \beta 4$ are actin monomersequestering proteins (Yu et al., 1993), accumulated evidence demonstrates that $\mathrm{T} \beta 10$ exerts different effects on the cellular function in comparison to $T \beta 4$. $T \beta 10$ suppresses angiogenesis by inhibiting vascular endothelial growth factor (VEGF)-induced endothelial cell proliferation via its interaction with Ras (Lee et al., 2005), whereas $T \beta 4$ is a potent enhancer of angiogenesis (Philp et al., 2004). An overexpression of $\mathrm{T} \beta 10$ decreases cell growth and induces apoptosis in ovarian cancer cell lines (Kim et al., 2012), while T $\beta 4$ mediates the prevention of apoptotic cell death induced in cardiomyocytes and endothelial progenitor cells (Bock-Marquette et al., 2004; Zhao et al., 2011). T $\beta 10$ inhibits the cell migration of human endothelial cells (Mu et al., 2006). In contrast, $\mathrm{T} \beta 4$ promotes cell migration by producing matrix metalloproteinase and downregulating E-cadherin (Wang et al., 2003; Ookuma et al., 2013). In addition, T $\beta 10$ is expressed in embryonic organs and modulates embryological development (Lin et al., 1990; Hall 1991; Gerosa et al., 2010; Fanni et al., 2011). Although $\mathrm{T} \beta 10$ appears to have various functions in different cells, including embryonic cells, there is little knowledge regarding the detailed expression pattern, possible roles and mechanisms of $\mathrm{T} \beta 10$ in tooth germ development.

In this study, the expression pattern of $T \beta 10$ in the course of tooth development from initiation to root formation was examined to elucidate the possible functional roles of $\mathrm{T} \beta 10$ in comparison to $T \beta 4$. Furthermore, a T $\beta 10$ knockdown assay was performed in cultured E11.0 mandibles and E15.0 tooth germs using treatment with siRNA, to confirm whether $T \beta 10$ actually participates in tooth germ development.

Fig. 1. In situ expression of $T \beta 10$ and $T \beta 4$ in the tooth germ at fetal stages. The in situ T $\beta 10$ expression was temporally and spatially stagespecific during the tooth germ development (left panels: $\mathbf{A}, \mathbf{C}, \mathbf{E}, \mathbf{G}, \mathbf{I}, \mathbf{K}, \mathbf{M}, \mathbf{O}$ ). The expression pattern was different from that of $\mathrm{T} \beta 4$ (right panels: $\mathbf{B}, \mathbf{D}, \mathbf{F}, \mathbf{H}, \mathbf{J}, \mathbf{L}, \mathbf{N}, \mathbf{P})$. (A,C) An expression of $\mathrm{T} \beta 10$ was diffusely observed in the subepithelial mesenchymal cells. Strong T $\beta 10$-positive mesenchymal cells were observed to aggregate beneath the mucosal epithelium (arrow) on E10.5 and E12.0. (B,D) On E10.5 and E12.0, a strong Tß3 expression was seen in the oral mucosal epithelial layer at the site where the tooth germ would form (arrow). (E) On E13.5, the T $\beta 10$ expression was diffusely found in the enamel organ and the surrounding mesenchymal cells (arrow). (G) On E14.0, a strong T $\beta 10$ expression was seen in the mesenchymal cells surrounding the epithelial tooth bud (arrow), and a weak T $\beta 10$ expression was observed in the epithelial cells in the central area of the tooth bud. $(\mathbf{F}, \mathbf{H})$ The T $\beta 4$ expression was localized in the epithelial tooth bud (arrow) and the mucosal epithelial layer on E13.5 and E14.0. (I,K) On E14.5 and E15.5, a strong $T \beta 10$ expression was localized in the dental papilla (asterisk) and the outer enamel epithelium cells of the enamel organ (arrow). $(\mathbf{J}, \mathbf{L}) A$ strong $T \beta 4$ expression was demonstrated in the outer enamel epithelium (arrow) on E14.5 and E15.5. The Tß4 expression in the primary enamel knot (arrowhead) observed on E14.5 had disappeared by E15.5. (M,0) On E16.5 and E18.0, a strong T $\beta 10$ expression was detected in the dental papilla at the presumptive cusps (asterisks), and a weak expression was also observed in the inner enamel epithelium (arrowheads). (N,P) On E16.5 and E18.0, a strong Tß4 signal was partly expressed in the outer enamel epithelium (arrow), and a weak T $\beta 4$ expression was found in the inner enamel epithelial cells (arrowheads). Li; lingual side, Bu; buccal side. Scale bars, $100 \mu \mathrm{m}$.

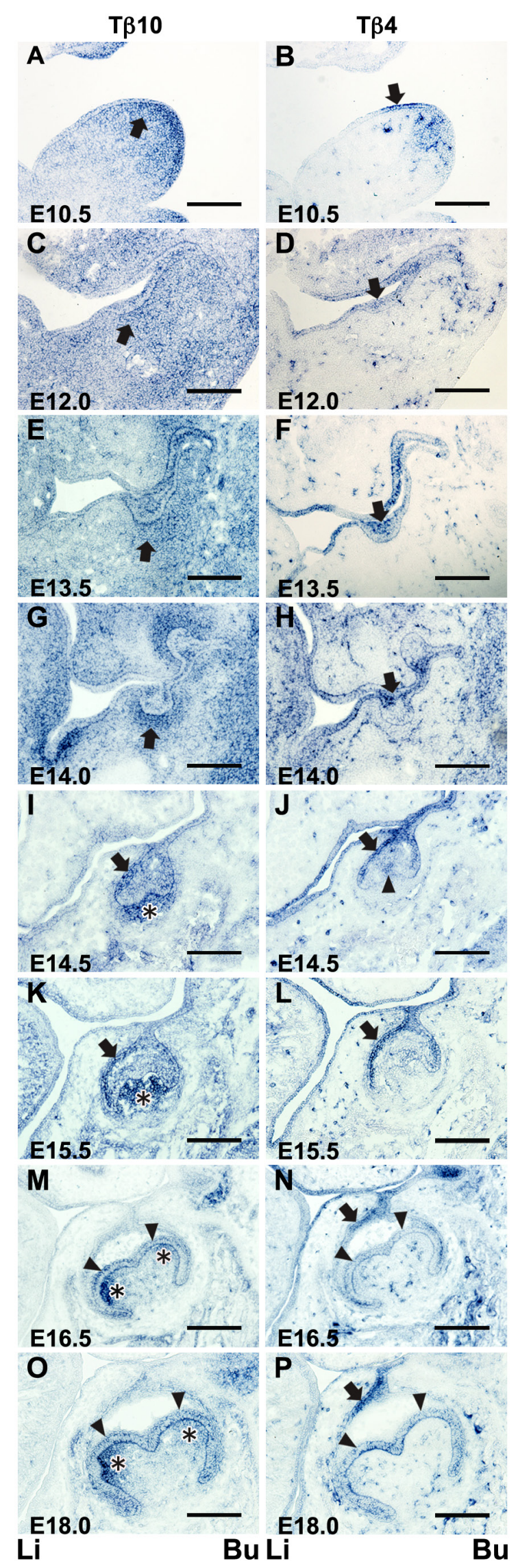




\section{Results}

\section{In situ hybridization of $\mathrm{T} \beta 10$ and $\mathrm{T} \beta 4$ in the developing tooth} germ

\section{Embryonic stages}

Initiation (E10.5)

Thickening of the oral mucosal epithelium to form the tooth bud was not apparent on this embryonic day.

A strong expression of $T \beta 10$ was diffusely observed in the subepithelial mesenchymal cells. A weak $T \beta 10$ expression was also detected in the oral mucosal epithelial cells (Fig. 1A).

In contrast, a strong $T \beta 4$ expression was detected in the oral mucosal epithelial cells localized at the site where the tooth bud had formed. A weak expression of $T \beta 4$ was observed in the blood vessels (Fig. 1B).

\section{Thickening of the dental epithelium (E12.0)}

Local epithelial thickening was observed in the oral mucosal epithelium, indicating the tooth bud formation.

An in situ expression of $T \beta 10$ was diffusely observed in the mesenchymal tissue (Fig. 1C). Strong $T \beta 10$-positive mesenchymal cells were to aggregate around the thickened mucosal epithelium (Fig. 1C, arrow). A weak T $\beta 10$ expression was also detected in the oral mucosal epithelial cells.

The T $\beta 4$ expression was observed in the oral mucosal epithelial cells, including those located at the site of the presumptive tooth bud. The $T \beta 4$ expression was also detected in the blood vessels in the mesenchymal tissue (Fig. 1D).

\section{Bud stage (E13.5 - E14.0)}

The thickened dental epithelium invaginated into the mesenchyme and formed the tooth bud.

A strong $T \beta 10$ expression was primarily observed in the mesenchymal cells that surrounded the invaginated epithelial tooth bud in the E13.5 mandible. A weak expression was noted in the mesenchymal cells that were diffusely distributed in the mandibular tissue. A weak $T \beta 10$ expression was also observed in the epithelial

Fig. 2. In situ expression of $T \beta 10$ and $T \beta 4$ in the developing tooth germ at the late bell stage. T $\beta 10$ expression from $P O$ to $P 3$ is presented in $(A, C, E, F, G, N$ and $P)$. T $\beta 4$ expression is indicated in $(B, D, H, I, J, O$ and Q). (A) On PO, T $\beta 10$ was expressed in the inner enamel epithelial cells (arrowheads) and preodontoblasts in the lingual cusp site of the dental pulp (arrow). (B) A strong T $\beta 4$ expression was detected throughout the inner enamel epithelial layer (arrowheads) on PO. (C) On P1, a strong T $\beta 10$ expression was detected in the buccal cusp site and the central groove region. $(\mathbf{E}, \mathbf{F}, \mathbf{G})$ The left, middle and right boxed areas in $(C)$ are shown at a higher magnification, respectively. (E) The T $\beta 10$ expression was reduced in the odontoblasts (white arrow) and ameloblasts (white arrowhead) in the lingual cusp where formed matrices were seen. (F) A strong T $\beta 10$ expression was detected in the preodontoblasts (arrow) and preameloblasts (arrowhead) in the central groove region (G) A strong $\mathrm{T} \beta 10$ expression was detected in the preodontoblasts (arrow) and preameloblasts (arrowhead) in the buccal cusp site. (D) A strong Tß4 signal was demonstrated in the inner enamel epithelial layer only on P1. (H,I,J) The left, middle and right boxed areas in (D) are shown at a higher magnification, respectively. $(\mathbf{H})$ The T $\beta 4$ expression was reduced in the ameloblasts in the lingual cusp with matrix formation. (I,J) A strong T $\beta 4$ expression was detected in the preameloblasts (arrowhead) in the central groove region and the buccal cusp site. (K, $\mathbf{L}, \mathbf{M})$ The HE-stained images correspond to $(\mathbf{E}, \mathbf{H}),(\mathbf{F}, \mathbf{I})$ and $(\mathbf{G}, \mathbf{J})$, respectively. $(\mathbf{K})$ Matrix formation was noted between ameloblasts and odontoblasts. (L,M) No matrix formation was seen in these regions. (N,P) On P2 and P3, a strong T $\beta 10$ expression was observed in preodontoblasts (arrows) and preameloblasts (arrowheads) at the lateral side of the tooth germ. $(\mathbf{0}, \mathbf{Q})$ The T $\beta 4$ expression was located in the preameloblasts (arrowheads) at the lateral side of the tooth germ at P2 and P3. Li; lingual side, Bu; buccal side. Scale bars, (A-D,N-Q) $100 \mu \mathrm{m}$; (E-M) $10 \mu \mathrm{m}$
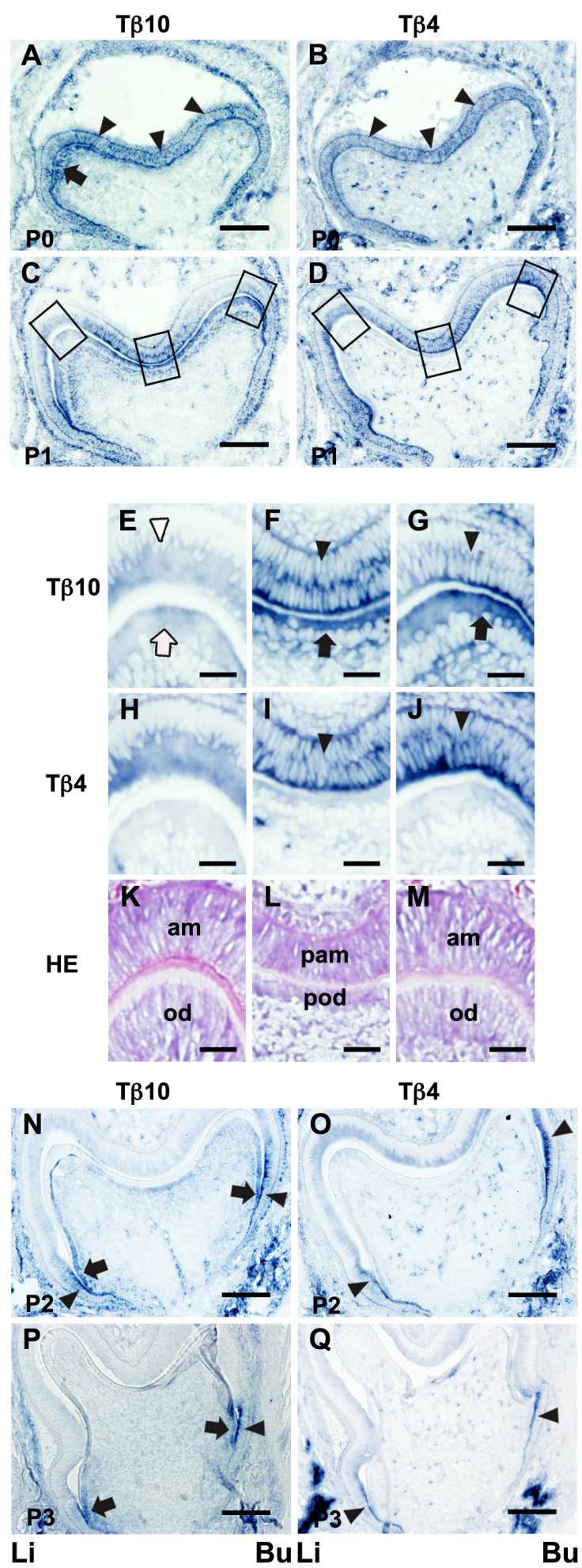
cells in the central area of the tooth bud (Fig. 1E).

In contrast, an in situ expression of $T \beta 4$ was localized in the invaginated epithelial tooth bud as well as in the mucosal epithelial layer. The $T \beta 4$ expression was hardly observed in the mesenchymal cells located around the tooth bud, with the exception of the blood vessels (Fig. 1F).

The in situ expression patterns of both $T \beta 10$ and $T \beta 4$ in the E14.0 mandible were coincident to those observed in the E13.5 mandible (Fig. $1 \mathrm{G}, \mathrm{H}$ ).

\section{Cap stage (E14.5 - E15.5)}

The enamel organ showed a cap-shaped structure at this stage.

A strong in situ expression of $T \beta 10$ was observed in the dental papilla cells in both the E14.5 (Fig. 1I) and E15.5 (Fig. 1K) mandibles. A weak in situ signal was detected in the mesenchymal cells of the dental sac. The $T \beta 10$ expression was also observed in the outer enamel epithelium and inner cells of the enamel organ. No signals were detected in the primary enamel knot (Fig. 1I).

A strong in situ expression of $T \beta 4$ was demonstrated in the outer enamel epithelium and primary enamel knot. A strong signal

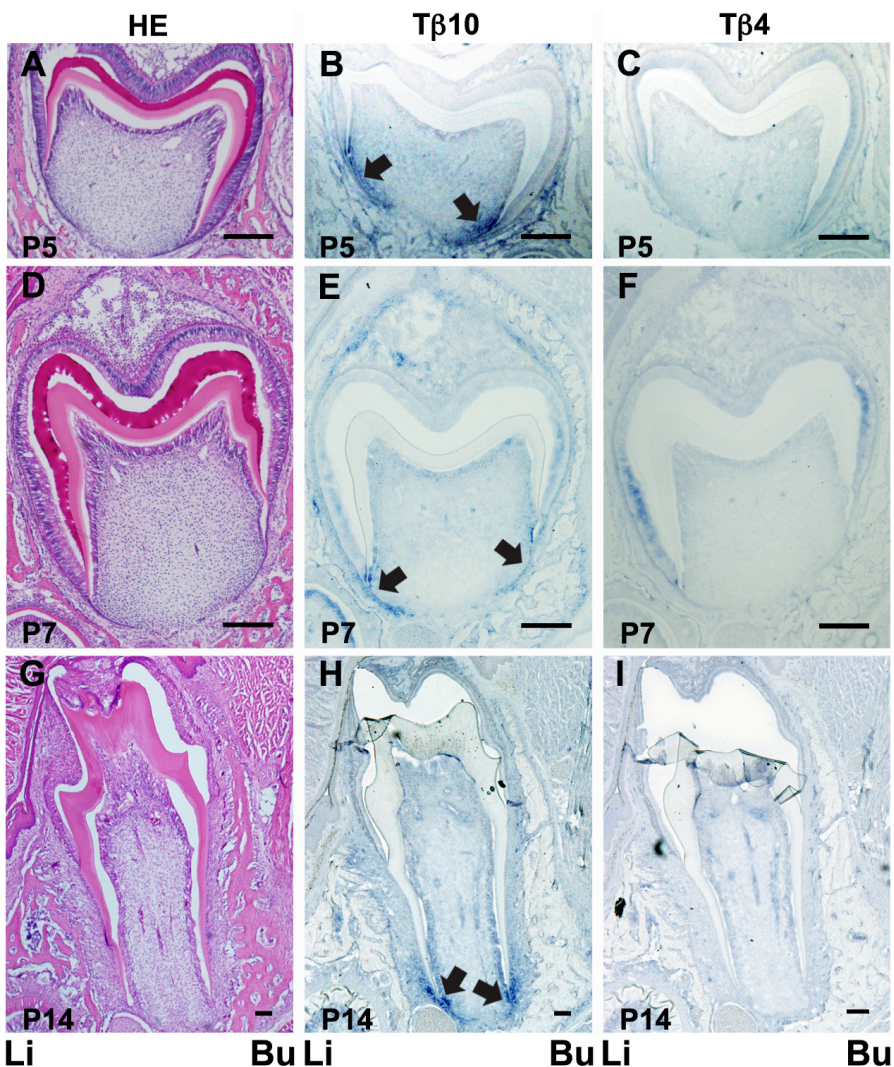

Bu Li
TABLE 1

\section{THE EFFECTS OF T $\beta 10$ INHIBITION ON THE DEVELOPMENT OF THE TOOTH GERM IN CULTURED E11.0 MANDIBLES}

\begin{tabular}{cccc} 
& \multicolumn{4}{c}{ Treatment } \\
\cline { 2 - 4 } Stage & Ut & $\mathbf{C}$ & $\mathbf{T \beta 1 0}^{\text {** }}$ \\
\hline Bud & 1 & 1 & 10 \\
Cap & 7 & 8 & 2 \\
\hline
\end{tabular}

Developmental arrest of tooth germ was significantly demonstrated in T $\beta 10$ in comparison to Ut and $C\left({ }^{\star \star} P<0.01\right)$. Ut: untreated explants, $C$ : explants treated with universal negative control siRNA $\mathrm{T} \beta$ 10: explants treated with siRNA for T $\beta 10$, Bud: bud-like stage, Cap: cap-like stage.

was also noted in the dental lamina and oral mucosal epithelium. A weak in situ signal was detected in the inner enamel epithelium (Fig. 1J).

The expression patterns of both $T \beta 10$ and $T \beta 4$ in the E15.5 mandible (Fig. $1 \mathrm{~K}, \mathrm{~L}$ ) were almost identical to those at E14.5. However, a higher positive intensity of the in situ $T \beta 10$ signal was detected in the dental papilla cells (Fig. 1K). No T $\beta 4$ expression was found in the enamel knot (Fig. 1L).

\section{Bell stage (E16.5 - E18.0)}

The periphery of the enamel organ extended to the mesenchymal tissue, resulting in the shape of a bell in the enamel organ.

On E16.5, a strong $T \beta 10$ expression was demonstrated in the dental papilla localized at the site where the cusps had formed (Fig. $1 \mathrm{M}$ ). A weak T $\beta 10$ expression was also observed in the inner enamel epithelium and the dental sac, while there was an undetectable level of the $T \beta 10$ expression in the oral mucosal epithelium and the outer enamel epithelium in which the $T \beta 10$ expression was detected in the bud (Fig. $1 \mathrm{C}, \mathrm{E}$ ) and cap stages (Fig. $1 \mathrm{I}, \mathrm{K}$ ).

$T \beta 4$ was strongly expressed in the dental lamina and the outer enamel epithelium on E16.5. A weak T $\beta 4$ expression appeared in the inner enamel epithelium. No apparent $T \beta 4$ expression was detected in the dental papilla, except for in the blood vessels (Fig. $1 \mathrm{~N}$ ).

The expression patterns of $T \beta 10$ and $T \beta 4$ on E18.0 (Fig. 1 O,P) were coincidental with those observed in the E16.5 mandible.

\section{Postnatal stages}

Late bell stage (PO - P3)

The dental pulp cells facing the inner enamel epithelium differentiated into preodontoblasts. Neither enamel nor dentin matrices had formed on postnatal day 0 (P0), while the formation of both enamel and dentin matrices between ameloblasts and odontoblasts was seen at the presumptive cusp site in the P1 tooth germ. The cells in the stage just before matrix formation are termed preameloblasts and preodontoblasts, respectively (Byers et al., 1990).

On P0, T $\beta 10$ was expressed in the preodontoblasts localized at the presumptive cusp sites of the dental pulp. An in situ signal was also found in the inner and outer enamel epithelia (Fig. 2A). A strong $T \beta 4$ expression was detected throughout the inner enamel epithelium on P0. The outer enamel epithelium also exhibited weak positive signals (Fig. 2B).

On $\mathrm{P} 1$, strong $T \beta 10$ expression was observed in the preodontoblasts and preameloblasts localized at the presumptive buccal cusp site and the central groove region (Fig. 2 C,F,G,L,M). Meanwhile, the $T \beta 10$ signal intensity was reduced in the odontoblasts and ameloblasts in the presumptive lingual cusp site where matrix formation was detected (Fig. 2 E,K). 


\section{Initiation Thickening of Bud stage Cap stage} dental epithelium

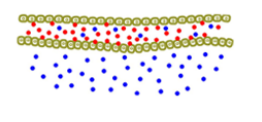

Early bell stage
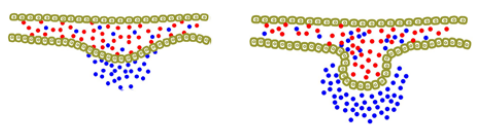

Late bell stage
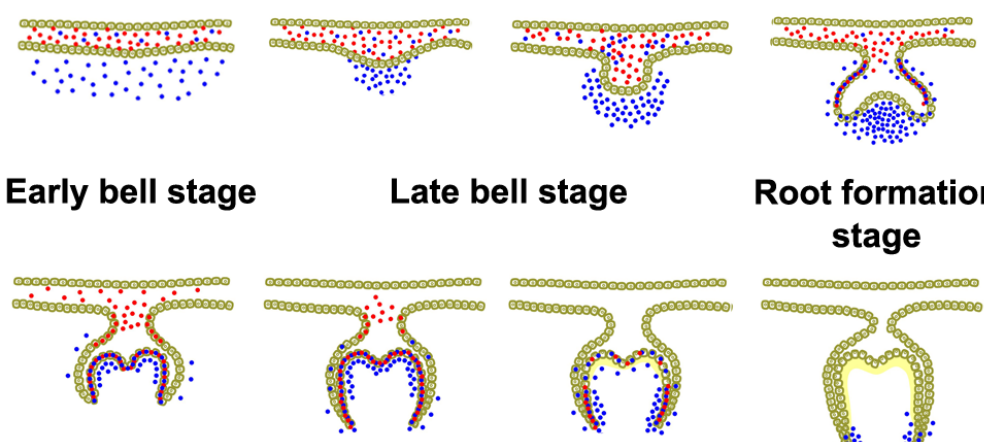

Root formation stage

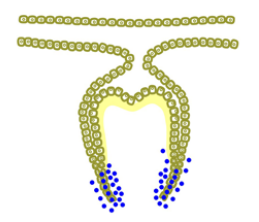

Fig. 4. Schematic illustration of $T \beta 10$ and $T \beta 4$ expression patterns observed during tooth development. The different expression patterns of $T \beta 10$ and $T \beta 4$ observed during tooth development are summarized. An in situT $\beta 10$ signal from the initiation stage to the cap stage was detected primarily in dental mesenchymal cells, while T $\beta 4$ was expressed in dental epithelial cells. Interestingly, T $\beta 10$-expressing preodontoblasts and T $\beta 4$-expressing preameloblasts faced each other in the tooth germ at the late bell stage. The T $\beta 10$ expression is indicated by blue dots, while the T $\beta 4$ expression is indicated by red dots. The yellow zone indicates the enamel and dentin matrices.

An in situ signal of $T \beta 4$ was observed through the inner enamel epithelial layer (Fig. 2D). A strong T $\beta 4$ expression was detected in the preameloblasts localized at the presumptive buccal cusp and the central groove sites where the strong $T \beta 10$ expression was exhibited (Fig. $2 \mathrm{I}, J)$. A weak $T \beta 4$ expression was observed in the ameloblasts located under the formation of the enamel matrix at the presumptive lingual cusp site (Fig. $2 \mathrm{H}, \mathrm{K}$ ). No in situ signals were found in preodontoblasts or odontoblasts on P1 (Fig. 2 D,H,I,J).

On P2, the $T \beta 10$ expression was observed in the odontoblastic layer (Fig. 2N). A highly strong expression was detected in the lateral sides of the dental pulp. A weak expression was found in the preodontoblasts located at the presumptive cusps and the occlusal

A

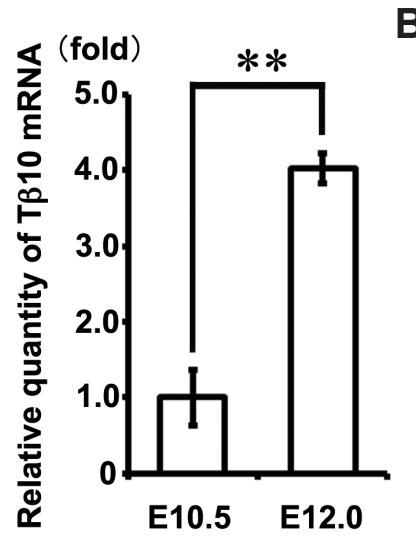

B

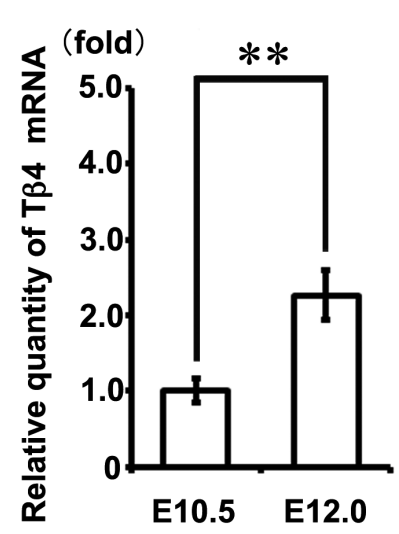

On P5 and P7, a strong T $\beta 10$ signal was demonstrated in preodontoblasts in a limited area of the lateral side of the tooth germ (Fig. 3 B,E). These preodontoblasts were considered to have originated before dentin matrix formation, as confirmed by observations of serial sections stained with hematoxylin and eosin (HE)(Fig. 3 A,D). In addition, a strong expression was especially seen in the HERS (Fig. $3 \mathrm{~B}, \mathrm{E}$ ).

There was almost no $T \beta 4$ expression in the crown at this stage (Fig. 3 C,F).

On P14, the root formation was almost completed (Fig. 3G). The T $\beta 10$ expression was observed only in the HERS (Fig. $3 \mathrm{H}$ ). The $T \beta 10$ expression was found in the dental pulp cells facing the $T \beta 10$-positive HERS. Periodontal ligament cells were also showed

Fig. 5 (Left). Increases in T $\beta 10$ and T $\beta 4$ mRNA levels in the mandible at E12.0 compared with those observed at E10.5. A real-time PCR analysis showed that the expression of T $\beta 10$ (A) and T $\beta 4$ (B) mRNAs were significantly increased in the mandible on E12.0 in comparison to those observed on E10.5. The data represent the mean \pm S.D. of more than three samples. ${ }^{*} \mathrm{P}<0.01$; versus $E 10.5$ mandibles.

Fig. 6 (Right). Inhibition of T $\beta 10$ gene expression using siRNA treatment. TheT $\beta 10$ mRNA expression was significantly decreased in the E11.0 mandible (A) and the E15.0 tooth germ (B) explants treated with TB10-siRNA (TB10-siRNA) in comparison to that observed in the untreated explants (Ut), or explants treated with universal negative control siRNA (Cont). The data represent the mean \pm S.D. of more than three samples. ${ }^{*} \mathrm{P}<0.05,{ }^{*} \mathrm{P}<0.01$. 
positive signals. No T $\beta 4$ expression was found in the crown and root (Fig. 3I). The characteristic expression patterns of both $T \beta 10$ and $T \beta 4$ in each stage are illustrated in Fig. 4.

\section{Quantification of $T \beta 10$ and $T \beta 4$ mRNA levels in the mandible using real-time PCR}

The mRNA level of T $\beta 10$ in the mandibles on E12.0 was increased approximately 4-fold in comparison to that observed on E10.5 (Fig. 5A, $p=0.0000013$ ). Similarly, a significant increase in the level of T $\beta 4$ mRNA in the mandibles on E12.0 was demonstrated in comparison to that observed on E10.5 (Fig. 5B, $p=0.0000091)$, thus confirming the findings of previous study (Yamaza et al., 2001).

Inhibition assay for T $\beta 10$ gene expression induced by siRNA treatment

The effects of siRNA on the expression of $T \beta 10$ were examined using semi-quantitative real-time PCR methods in the cultured E11.0 mandible and the E15.0 tooth germ on the 8th culture day. The T $\beta 10$ mRNA expression levels in both the E11.0 mandible and the E15.0 tooth germ explants treated with $T \beta 10$-siRNA were significantly decreased to approximately $50 \%$ compared with those observed in the untreated explants and the explants treated with universal negative control siRNA(Fig. $6 \mathrm{~A}, p=0.000035$ by one-way ANOVA, for each $p<0.01$ by Tukey-Kramer test; Fig. 6B, $p=0.019$ by one-way ANOVA, for each $p<0.05$ by Tukey-Kramer test).

\section{Histological analysis of cultured E11.0 mandibles and E15.0 tooth} germs treated with $\mathrm{T} \beta 10-$ siRNA

In the controls, the epithelium appeared to form a cap-shaped structure on the 8th culture day. In addition, both dental papilla and dental follicle formed by the surrounding mesenchymal cells were observed (Fig. 7 A,B). The mandibles treated with T $\beta 10$ siRNA exhibited a developmental arrest of the enamel organ and continued to show the bud-like stage on the 8th culture day
TABLE 2

\section{EFFECTS OF T $\beta 10$ INHIBITION ON THE DEVELOPMENT OF THE DENTAL PAPILLA IN CULTURED E15.0 MANDIBLES}

\begin{tabular}{ccccc} 
& & \multicolumn{3}{c}{ Treatment } \\
\cline { 3 - 5 } Stage & & Ut & C & T及10 $^{\text {** }}$ \\
\hline \multirow{2}{*}{ Bell } & + & 7 & 14 & 9 \\
& - & 0 & 1 & 7 \\
\hline
\end{tabular}

Developmental arrest of dental papilla was significantly demonstrated in T $\beta 10$ in comparison to Ut and $C\left({ }^{*} P<0.05\right)$. Ut: untreated explants, $C$ : explants treated with universal negative control siRNA $T \beta 10$ : explants treated with siRNA for $T \beta 10,+$ : positive findings, -: negative findings.

(Fig. 7C). The development of the tooth germ was significantly suppressed in the E11.0 mandibles treated with T $\beta 10$-siRNA compared with that observed in the controls ( $p=0.00059$, Table 1).

Tooth germs obtained from E15.0 embryos were also cultured for eight days with siRNA treatment. In the controls, the tooth germs appeared to form a bell-shaped structure on the 8th culture day. The formation of a predentin matrix was observed (Fig. 7 $\mathrm{D}, \mathrm{E})$. Meanwhile, significant suppression of tooth germ growth was demonstrated in the explants treated with T $\beta 10$-siRNA in comparison to that observed in the controls $(p=0.013$, Table 2 , Fig. $7 \mathrm{D}-\mathrm{F}$ ). However, treatment with $T \beta 10$-siRNA did not influence the morphology or arrangement of ameloblasts and odontoblasts. Predentin matrix formation was also observed in all of the controls and explants treated with T/10-siRNA (Fig. $7 \mathrm{G}-\mathrm{I}$ ). These findings suggest that $T \beta 10$ may not affect the differentiation of ameloblasts or odontoblasts.

Ki67 immunohistochemical and TUNEL staining in cultured E11.0 mandibles and E15.0 tooth germs treated with T $\beta 10$-siRNA

Since the development of the tooth germs in the E11.0 mandibles and the E15.0 tooth germs was disturbed by treatment with $T \beta 10$-siRNA, cell proliferation and cell death were examined in the tissue specimens.

In the cultured E11.0 mandibles, the numbers of Ki67- or
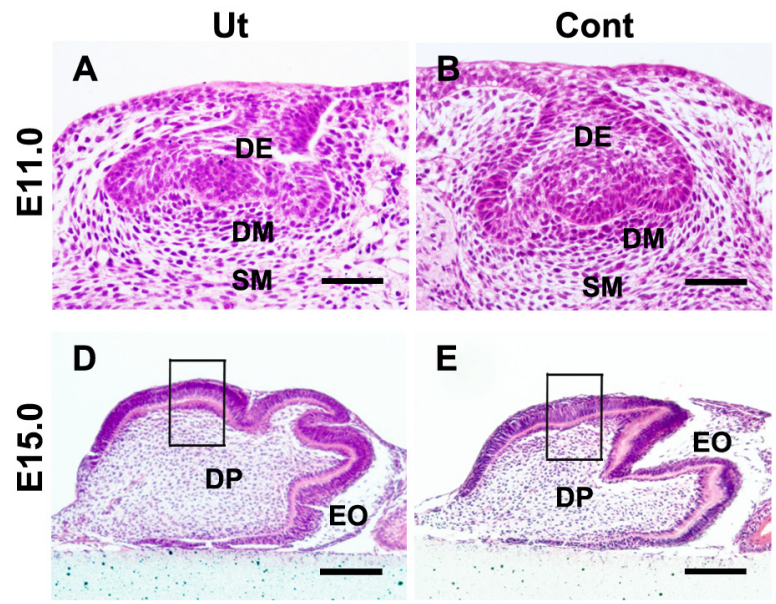

E
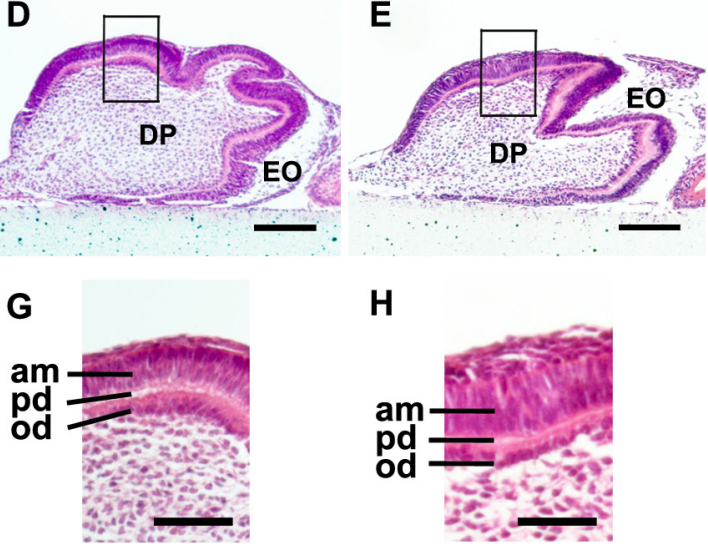

H

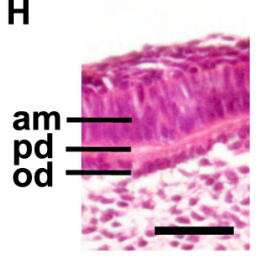

\section{TB10 SiRNA}

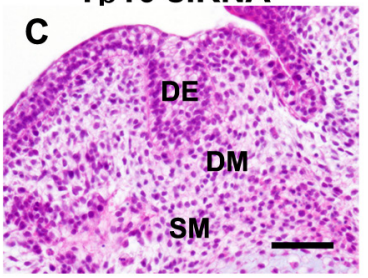

F

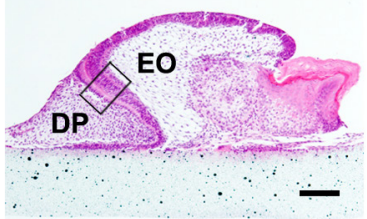

I

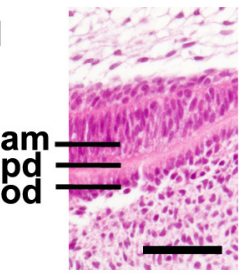

Fig. 7. Suppressed morphogenesis of the tooth germ in cultured E11.0 mandibles and E15.0 tooth germs treated with $\mathbf{T} \boldsymbol{\beta} \mathbf{1 0}$-siRNA. An inhibitory assay for T $\beta 10$ was performed using T $\beta 10$-siRNA in cultured E11.0 mandibles (A,B,C) and E15.0 tooth germs (D,E,F) for eight days. $(\mathbf{A}, \mathbf{B})$ In the E11.0 mandibles, untreated explants (Ut) and explants with universal negative control siRNA (Cont) revealed a cap-like formation of the tooth germ. (C) No further development of the tooth germ was observed in the T $\beta 10$-siRNA-treated explants (TB10-siRNA). (D,E) In the E15.0 tooth germs, Ut and Cont revealed tooth germs with a bell-like appearance, ameloblastand odontoblast differentiation and predentin matrix formation. (F) Some Tß10-siRNAs did not show tooth germs with a bell-like appearance. $(\mathbf{G}, \mathbf{H}, \mathbf{I})$ Each image shows a higher magnification of the boxed area in $(D, E, F)$ respectively. No apparent differences were observed in the morphology or arrangement of ameloblasts and odontoblasts, or the formation of predentin among Ut, Cont and TB10-siRNA. DE; dental epithelium, DM; dental mesenchyme, SM; surrounding mesenchyme, $D P$; dental papilla, EO; enamel organ, am; ameloblasts, pd; predentin, od; odontoblasts. Scale bars, (A-F) 100 $\mu \mathrm{m} ;$ (G-I) $50 \mu \mathrm{m}$. 
terminal deoxynucleotidyl transferase-dUTP nick end labeling (TUNEL)-positive cells and the total cell numbers were counted in three objective areas: the "dental epithelium (DE)", the "dental mesenchyme (DM)" and the "surrounding mesenchyme (SM)". The DM was either the "DP and follicle" in the cultured explants showing the normal cap-like tooth germ or the "odontogenic ectomesenchyme" in the explants exhibiting an inhibition of tooth germ development (Figs. 7 and 8) (Takahashi et al., 2010; Ookuma et al., 2013).

The localization of $T / \beta 10$-expressing cells corresponded well with that of the Ki67-positive cells in the cultured mandible and tooth germ of the control and/or untreated samples. Furthermore, the immunohistochemical reactivity for Ki67 in the E11.0 mandibles revealed a significant decrease in cell proliferation activity in the
DE, DM and SM of the T $\beta 10$-siRNA-treated explants in comparison to that observed in the controls. TUNEL-positive cells were also observed in both the controls and the explants treated with T $\beta 10$-siRNA. However, there were no significant differences in apoptotic cells among the examined groups.

The cultured E15.0 tooth germs were composed primarily of two areas: the "enamel organ (EO)" and the "dental papilla (DP)" (Figs. 7 and 8). The numbers of cells in these areas were counted. Immunohistochemical reactivity for Ki67 in the E15.0 tooth germs revealed a significant decrease in the cell proliferation activity of the EO and DP in the T $\beta 10$-siRNA-treated explants in comparison to that observed in the controls. In the TUNEL staining, there were no significant differences in apoptotic cells among the examined groups.
A

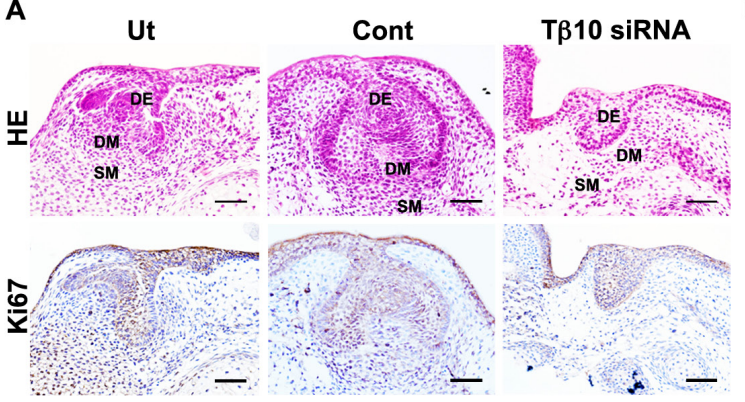

C

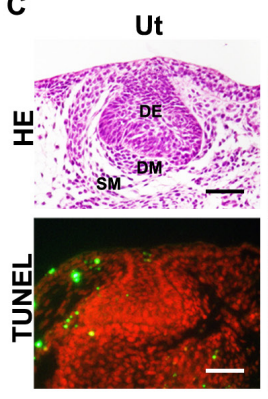

Cont

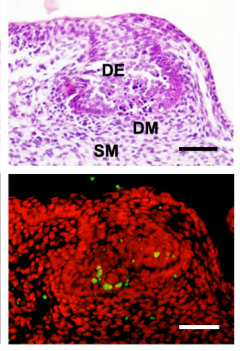

Tß10 SIRNA

E

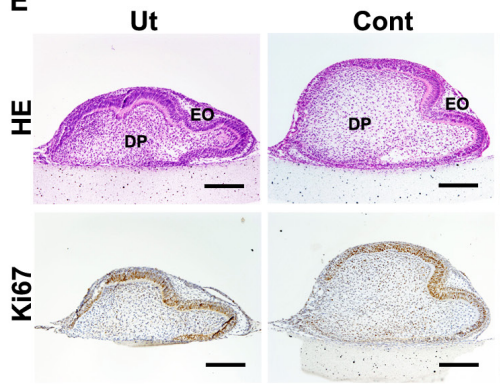

G

G Ut

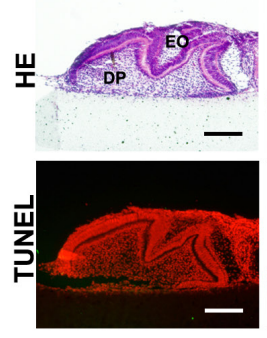

Cont
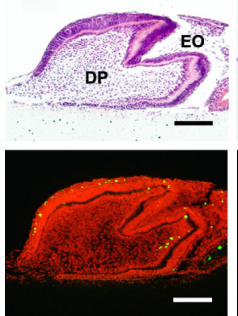
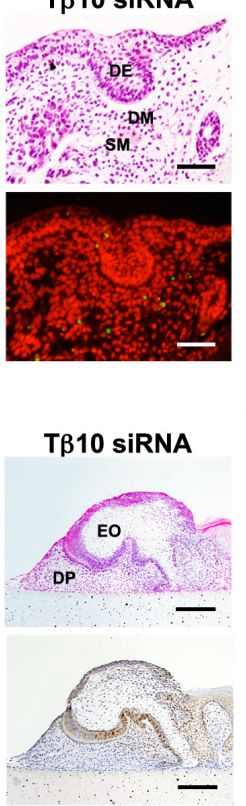

T $\beta 10$ siRNA

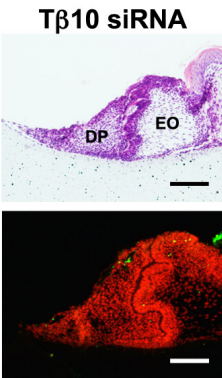

B

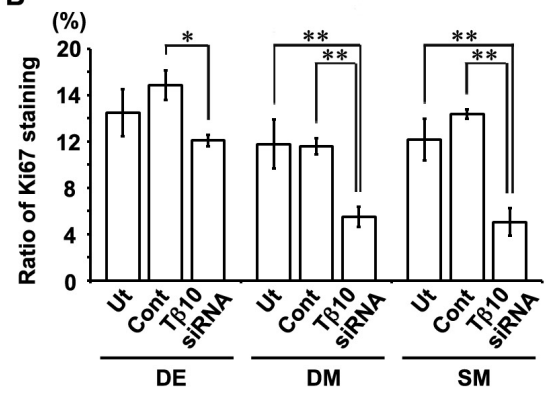

D

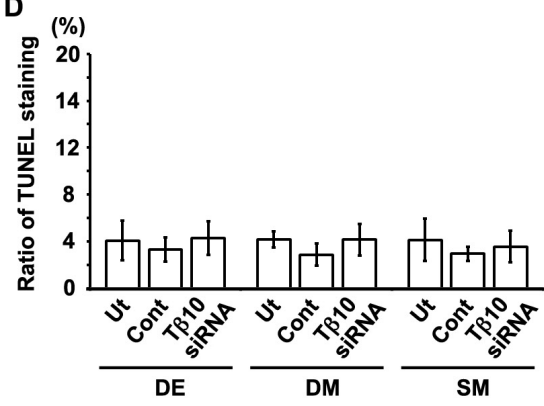

F (\%)

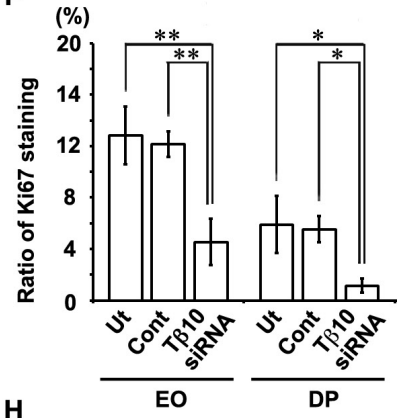

H (\%)

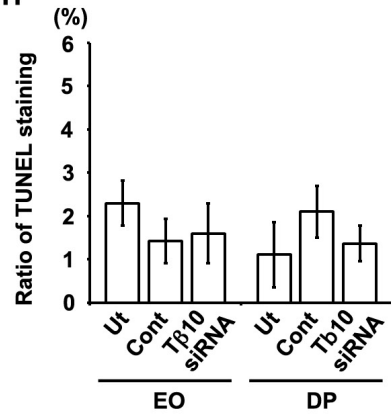

Fig. 8. Cell proliferation and cell death activity in cultured E11.0 mandibles and E15.0 tooth germs treated with TR10-siRNA. A cell proliferation assay was performed to analyze the involvement of TB10 in the morphogenesis of the cultured E11.0 mandibles (A-D) and E15.0 tooth germs $(\mathbf{E}-\mathbf{H})$ on the 8th day. $(\mathbf{A}, \mathbf{E})$ Ki67 immunostaining (lower panel) and HE staining (upper panel) are presented in the untreated explants $(U t)$ and explants treated with universal negative control siRNA (Cont) or TB10-siRNA (Tß10-siRNA). (C,G) TUNEL staining (lower panel) and HE staining (upper panel) are presented in the Ut, Cont and Tß10-siRNA. (B) Significant decreases in the ratios of the number of Ki67-positive cells to the total cell number (ratio of Ki67 staining) were observed in the DE, DM and SM areas of the TB10-siRNA in comparison to those observed in the Ut and Cont. (C) TUNEL-positive cells (green) were primarily observed in the primary enamel knot and scattered in both the epithelium and mesenchyme of the Ut and Cont. (D) There were no significant differences in the ratios of the number ofTUNEL-positive cells to the total cell number (ratio of TUNEL staining) in the objective areas among the Ut, Cont and TR10-siRNA. (F) Significant decreases in the ratios of Ki67 staining were observed in the EO and DP areas of the TR10-siRNA in comparison to those observed in the Ut and Cont. (G) TUNEL-positive cells were scattered in both the epithelium and mesenchyme of the examined explants of $U t$, Cont and T $\beta 10-$ siRNA. (H) There were no significant differences in the ratios of TUNEL staining in the objective areas among the Ut, Cont and T $\beta 10-s i R N A$. DE; dental epithelium, DM; dental mesenchyme, $S M$; surrounding mesenchyme, DP; dental papilla, EO; enamel organ. Scale bars: 100 um. ${ }^{*} \mathrm{P}<0.05,{ }^{*} \mathrm{P}<0.01$. 

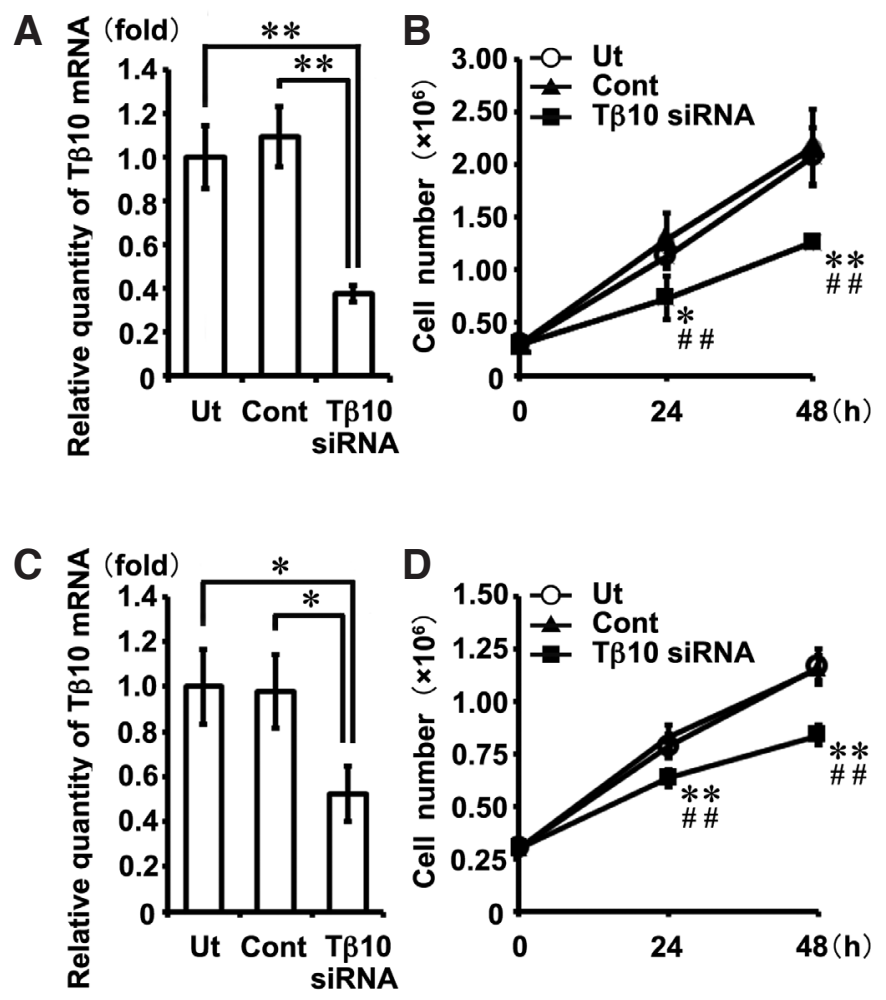

Fig. 9. Effects of TB10-siRNA on the cell proliferation of tooth germderived cells. A cell proliferation assay of tooth germ-derived cells, $\mathrm{MDP}$ $(\mathbf{A}, \mathbf{B})$ and $m D E 6(\mathbf{C}, \mathbf{D})$ cells, was performed with or without T $\beta 10$-siRNA treatment. (A) The level of T $\beta 10$ transcripts in the mDP cells treated with T $\beta 10$-siRNA (Tß10-siRNA) were significantly reduced in comparison to those observed in the untreated explants $(U t)$ and explants treated with universal negative control siRNA (Cont) $\left.{ }^{* *} \mathrm{P}<0.01\right)$. (B) At 24 and $48 \mathrm{~h}$ after transfection with siRNA, the cell numbers of TB10-siRNA were significantly lower than those of Ut $\left({ }^{*} \mathrm{P}<0.05,{ }^{*} \mathrm{P}<0.01\right)$ or Cont (\#P<0.05, \#\#P<0.01). (C) Significant decreases in the levels of T $\beta 10$ transcripts were also observed in the mDE6 cells treated with T $\beta 10$-siRNA ( $\left.{ }^{*} \mathrm{P}<0.01\right)$. (D) In the mDE6 cells, similar effects of T $\beta 10-$ siRNA on the cell proliferation were observed at 24 and $48 \mathrm{~h}$ after transfection with siRNA $\left({ }^{*} \mathrm{P}<0.05,{ }^{*} \mathrm{P}<0.01\right.$; versus $U t$, \#P<0.05, \#\#P<0.01; versus Cont).

Effects of TB10-siRNA on the proliferative activity of $\mathrm{mDP}$ and $m D E 6$ cells

To confirm the effects of $T \beta 10$-siRNA on cell proliferation activity, a cell growth assay was performed using mDP and mDE6 cells, which are mouse dental pulpal and epithelial cell lines established from tooth germs, respectively (Tsubakimoto et al., 2007; Yoshizaki et al., 2008).

A significant reduction in the T $\beta 10$-mRNA expression level was observed in the mDP cells with respect to T $\beta 10$-siRNA-treated explants in comparison with that observed in the controls (Fig. 9A). The cell proliferation activity level was significantly lower in the $\mathrm{mDP}$ cells treated with $T \beta 10$-siRNA than in the controls at both 24- and 48-hour culture periods, thus indicating that $T \beta 10$-siRNA treatment affects the cell proliferative activity of tooth germ development (Fig. 9B). Similar effects of T $\beta 10$-siRNA on the mRNA expression were observed in the mDE6 cells (Fig. 9C). Significant suppression of the cell proliferation activity at both 24 and at $48 \mathrm{~h}$ was also noted in the T $\beta 10$-siRNA-treated mDE6 cells in comparison to that observed in the controls (Fig. 9D).
On the other hand, T $\beta 10$-siRNA treatment showed no effects on the expressions of dentin matrix protein-1 (Dmp-1) or dentin sialophosphoprotein (Dspp) in the mDP cells (Supplementary Fig. 1 $A, B)$. The expression of amelogenin (Amel) in the mDE6 cells was not affected by $T \beta 10$-siRNA treatment (Supplementary Fig. 1C).

Since both $T \beta 10$ and $T \beta 4$ are known to be actin monomersequestering proteins (Yu et al., 1993), the influence of T $\beta 10$-siRNA treatment on the change in the ratio of G-/F-actin in the $\mathrm{mDP}$ and mDE6 cells was evaluated. Treatment with T $\beta 10$-siRNA for $48 \mathrm{~h}$ decreased the ratio of $\mathrm{G}$-/F-actin in the $\mathrm{mDP}$ cells, while the ratio of G-/F-actin modestly changed in the mDE6 cells (Supplementary Fig. $2 \mathrm{~A}, \mathrm{~B})$. The $T \beta 10$ expression level in the mDP cells was higher than that observed in the mDE6 cells, although real-time PCR revealed that there was no significant difference between the cells. Meanwhile, the T $\beta 4$ expression level in the mDP cells was less than one-third of that observed in the mDE6 cells. A significant difference was noted between these values (Supplementary Fig. 2 C,D).

These results indicate the possibility that T $\beta 10$-siRNA treatment induces the arrest of tooth germ development caused by the decreased cell proliferative activity rather than regulating the cell differentiation of both dental epithelial and mesenchymal cells.

\section{Discussion}

Several studies have reported the existence of a close relationship between the expression of $\mathrm{T} \beta 10$ and organogenesis (Lin et al., 1990; Hall 1991; Gerosa et al., 2010; Fanni et al., 2011). However, there are no articles describing the relationship between tooth germ development and the T $\beta 10$ expression.

Previous studies (Akhter et al., 2005; Ookuma et al., 2013) demonstrated that $\mathrm{T} \beta 4$, another member of the beta-thymosin family, participates in the morphogenesis of the tooth germ. However, the in situ expression pattern of $T \beta 10$ apparently differs from that of $T \beta 4$. In this study, the expression of $T \beta 4$ was primarily observed in the epithelial elements. On the other hand, $T \beta 10$ was expressed in the dental papilla in the E15.5 tooth germ (Akhter et al., 2005).

We reconfirmed that the in situ expression pattern of $T \beta 10$ from the early to the middle developmental stage (E10.5-E18.0) apparently differs from that of $T \beta 4$. Carpintero et al., (1996) reported that the in situ expression of $T \beta 10$ in the $E 9.5$ mouse embryo is detected primarily in the mesenchymal tissue, including the maxilla and mandible. This expression pattern is coincident with that observed in our present study in which T $\beta 10$ mRNA was primarily detected in the mesenchymal tissue of the mandible on E10.5. The T $\beta 10$ expression has also been reported to exist in the developing renal proximal and distal tubules (Gerosa et al., 2010), and the acinar and ductal epithelial cells of developing salivary gland (Fanni et al., 2011). Therefore, it may be reasonable to consider that $\mathrm{T} \beta 10$ may relate to the growth of mesenchymal tissue as well as epithelial cells in the organogenesis and development of the tooth germ. Indeed, a knockdown assay for T $\beta 10$ in the E11.0 mandibles and the E15.0 tooth germs using siRNA resulted in the developmental arrest of the tooth germ. We further examined whether the developmental arrest of the tooth germ was caused by a disturbance in cell proliferation or an increase in cell death. Ki67 immunostaining showed that treatment with siRNA in the organ cultured E11.0 mandibles resulted in a significantly decreased ratio of Ki67 staining in the dental mesenchymal cells. The cell proliferative activity level evaluated with Ki67 immunostaining was suppressed in the 
dental epithelial cells. The T $\beta 10$-expressing areas corresponded to the localization of Ki67-positive cells. Therefore, treatment with T/10-siRNA appears to effectively suppress tooth germ development in cultured organs, thus resulting in the developmental arrest of the tooth germ in the E11.0 mandible and E15.0 tooth germ.

Furthermore, treatment with T $\beta 10$-siRNAalso showed decreased proliferative activity in the cultured mDP and mDE6 cells. Meanwhile, no significant increases in the number of TUNEL-positive cells were observed in the cultured E11.0 mandibles following treatment with T/10-siRNA. Therefore, the developmental arrest of the tooth germ observed in the cultured E11.0 mandibles might have been caused by a reduced cell proliferation activity rather than by cell death. These results indicate that $\mathrm{T} \beta 10$ may play important roles in cell proliferation in odontogenic epithelial and mesenchymal cells in the initiation and development of the tooth germ.

T $\beta 10$ is an actin monomer-sequestering protein (Yu et al., 1993), and therefore changes in the ratio of G-/F-actin were examined. Treatment with $T \beta 10$-siRNA changed the ratio of G-/F-actin in the mDP cells. T $\beta 10$-siRNA treatment might effectively suppress actin sequestering in the $\mathrm{mDP}$ cells due to the lower $T \beta 4$ expression in the mDP cells (Supplementary Fig. 2). Santelli et al., (2002) showed that blocking $\mathrm{T} \beta 10$ using an antisense methodology in human thyroid carcinoma cells significantly decreases anchorage-independent growth and improves actin filament organization. Thus, T $\beta 10$ may affect cell proliferation via the regulation of actin assembly. In the future study, it is necessary to clarify the detailed mechanisms underlying the actin arrangement and cell proliferation regulated by $\mathrm{T} \beta 10$ during tooth development.

Interestingly, the expression patterns of both $T \beta 10$ and $T \beta 4$ just before matrix formation were quite different in this study. As shown in Fig. 2, a strong expression of $T \beta 10$ was observed in preodontoblasts as well as in preameloblasts. In contrast, $T \beta 4$ was strongly expressed in preameloblasts only. Furthermore, preodontoblasts with a strong $\mathrm{T} \beta 10$ expression and preameloblasts with a strong T及4 expression exhibited face-to-face localization in the tooth germ. These findings suggest the presence of an intimate cell-cell interaction between $T \beta 10$-expressing preodontoblasts and $T \beta 4$ expressing preameloblasts mediated by two different thymosins in the formation of dentin and enamel matrices. Therefore, other new functions of $\mathrm{T} \beta 10$ and $\mathrm{T} \beta 4$ might exist that are not related to the development or differentiation of the tooth germ. The peculiar expression patterns of both $T \beta 10$ and $T \beta 4$ observed in the matrix formation stage indicate that these unknown functions are important for the growth of the tooth germ. Further examinations are needed to clarify the true functions of $T \beta 10$ and $T \beta 4$ in tooth germ development at this stage.

Both $T \beta 10$ and $T \beta 4$ also showed peculiar expression patterns in the root formation stage. In this stage, the expression of $T \beta 10$ was found in preodontoblasts at the lateral side of the tooth germ. In particular, the expression of $T \beta 10$ was localized in the dental epithelial cells and the dental mesenchymal cells of the dental pulp at the apex site of the enamel organ that formed the HERS after P5. The characteristic expression pattern of $T \beta 10$ observed at the root formation stage suggests that $\mathrm{T} \beta 10$ may participate in forming the outline of the tooth root and extending the HERS.

In conclusion, $T \beta 10$ and $T \beta 4$ exhibit developmental stage-specific temporal and spatial expression patterns in the tooth germ. These findings suggested that $\mathrm{T} \beta 10$ and $\mathrm{T} \beta 4$ might play different roles in mouse tooth germ development. Previous studies have shown that the immunolocalization of $\mathrm{T} \beta 10$ is altered cell by cell in the developing kidneys and salivary glands (Gerosa et al., 2010; Fanni et al., 2011). Fanni et al., (2011) reported the existence of a close relationship between the immunohistochemical expression of T $\beta 10$ and salivary gland development, and speculated that alternative immunoreactivity is associated with the organogenesis of the salivary glands. Our present study and previous reports indicate that $\mathrm{T} \beta 10$ and $\mathrm{T} \beta 4$ could potentially perform multiple functional roles in tooth germ development. However, the signal transduction pathways both up- and down-streams of $T \beta 10$ and $T \beta 4$ in tooth germ development remain unknown. Further examinations are needed to elucidate the complete functional roles of these beta-thymosins and the interactions between beta-thymosin-associated factors in tooth germ development.

\section{Materials and Methods}

\section{Animals}

At least three BALB/c embryos and postnatal mice at each developmental stage were used in this study. The examined developmental stages included E10.5, 11.0, 12.0, 13.5, 14.0, 14.5, 15.0, 15.5, 16.5 and 18.0 after gestation and P0, 1, 2, 3, 5, 7 and 14. Adult BALB/c mice were obtained from Charles River Japan, Inc. (Yokohama, Japan). All experimental procedures using mice were performed in accordance with the guidelines of the Animal Care and Use Review Committee of Kyushu University (Fukuoka, Japan). Adult female mice (10-20 weeks) were caged together with male mice. Successful insemination was determined based on the presence of a postcopulatory plug in the vagina $12 \mathrm{~h}$ later. The embryonic day E0.5 was defined by the presence of the vaginal plug (Takahashi et al., 2010; Ookuma et al., 2013).

\section{In situ hybridization}

To confirm the specificity and sensitivity of the antisense RNA probes for $T \beta 10$ and $T \beta 4$ mRNAs, membrane hybridization was performed. Membrane hybridization and in situ hybridization methods were carried out according to the protocol described in previous studies (Yamaza et al., 2001). Specific probes for T $\beta 10$ and T $\beta 4$ mRNAs were designed according to the NCBI Reference Sequences (accession number T $\beta 10$ : NM_025284.4, T $\beta 4$ : NM_021278.2) (Akhter et al., 2005). Strong and weak signals were used to describe for the relative evaluation of the signal intensity observed in the same tissue section. The developmental tooth germ process in the embryonic mandible was defined according to previous studies (Akhter et al., 2005; Takahashi et al., 2010).

\section{Semi-quantitative real-time PCR}

Total RNA was isolated from mandibles on E10.5 and E12.0, and from tooth germs on E15.0, E18.0, P1 and P5 using the SV Total RNA Isolation System (Promega, WI, USA). Total RNA was also isolated from cultured E11.0 mandibles, E15.0 tooth germs and mDP and mDE6 cells. cDNA was synthesized using the SuperScript ${ }^{\circledR}$ VILO $^{\text {TM }}$ cDNA Synthesis System (Invitrogen, CA, USA) according to the manufacturer's instructions. Realtime PCR was performed using a Thermal Cycler Dice ${ }^{\circledR}$ Real Time System

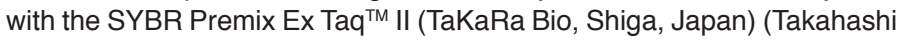
et al., 2010; Ookuma et al., 2013). The glyceraldehyde-3-phosphatedehydrogenase (GAPDH) gene was used as an endogenous reference gene. The gene-specific primers for T $\beta 10, T \beta 4$ and GAPDH were as follows: T/310, 5'-AAC GAG AGT GGG AGC ACC TG-3' and 5'-AGC TTG GCC TTA TCG AAG CTG-3'; T $\beta 4$, 5'-CTG ACA AAC CCG ATA TGG CTG A-3' and 5'-ACG ATT CGC CAG CTT GCT TC-3'; GAPDH, 5'-TGT GTC CGT CGT GGA TCT GA-3' and 5'-TTG CTG TTG AAG TCG CAG GAG-3'. The relative expression levels of each targeted gene were normalized using the delta-delta cycle threshold $(\mathrm{Ct})$ comparative method based on the reference gene values. The specificity of the PCR products was confirmed using a 
melting curve and/or gel electrophoresis (Takahashi et al., 2010; Naher et al., 2012; Ookuma et al., 2013).

\section{Inhibition assay for T $\beta 10$ using siRNA on organ culture}

The mandibles dissected from the E11.0 embryos and the tooth germs dissected from the E15.0 embryos were cultured for eight days. The culture period of both the E11.0 mandibles and E15.0 tooth germs was determined based on previous studies (Kobayashi et al., 2006; Xie et al., 2007; Ookuma et al., 2013). The protocols for organ culture were identical to those used in these studies. In order to inhibit the functions of $T \beta 10$ during tooth germ development, cultured explants were treated with siRNAs supplemented in the culture media according to the manufacturer's protocol of Lipofectamine RNAiMAX (Invitrogen)(Naher et al., 2012). siRNA for murine T $\beta 10$ (Mm_Tmsb10_0122) and a universal negative control siRNA (SigmaAldrich, St. Louis, MO, USA) were used as a target and negative control, respectively. $30 \mathrm{pmol}$ of siRNA and $3 \mu \mathrm{l}$ of Lipofectamine RNAiMAX were contained in 1-ml culture media (siRNA final conc. $30 \mathrm{nM}$ ). The culture medium was changed every $24 \mathrm{~h}$.

\section{Histological analysis of the cultured explants}

The cultured explants were fixed with $4 \%$ paraformaldehyde for $24 \mathrm{~h}$ at $4^{\circ} \mathrm{C}$ and then embedded in paraffin. Paraffin-embedded explants were cut into 5- $\mu \mathrm{m}$ thick sections in the anteroposterior direction, and HE staining was performed. The explants were prepared for the histological analysis as previously described (Kobayashi et al., 2006; Xie et al., 2007; Ookuma et al., 2013).

\section{Cell proliferation and cell death assays in the cultured organs}

In order to evaluate the effects of T $\beta 10$ on cell proliferation during tooth development, immunohistochemistry using a rabbit polyclonal antibody to Ki67 (Abcam, Cambridge UK) was performed. These sections were nuclear-counterstained with hematoxylin.

TUNEL was applied to detect apoptotic cells using the in situ Apoptosis Detection Kit (TaKaRa). Briefly, terminal deoxynucleotidyl transferase (TdT) enzymes were used on the sections of the cultured organs treated with siRNA, and then the sections were labeled with FITC on the nick sites in the DNA. Propidium iodide was then used for nucleus staining.

The percentages of Ki67-positive or FITC-positive cells were evaluated in the DE, DM and SM areas in the cultured E11.0 mandibles. In the cultured E15.0 tooth germs, the numbers of cells in the EO and DP areas were counted. More than one hundred cells were examined as a population of each area in at least three different explants. The number of stained cells was divided by the total number of stained and non-stained target cells to calculate the ratio of Ki67 or FITC staining. The analyses of cellular proliferation and cell death were carried out as described in previous studies (Takahashi et al., 2010; Ookuma et al., 2013).

\section{Cell lines and cell culture}

Mouse dental epithelial and pulpal cell lines established from tooth germs (named mDE6 and mDP, respectively) were kindly provided by Professor Satoshi Fukumoto (Tohoku University, Japan) and Associate Professor Masahiro Saito (Tokyo University of Science, Japan) (Tsubakimoto et al., 2007; Yoshizaki et al., 2008). Both types of cells were maintained in DMEM/F-12 (Invitrogen, CA, USA) supplemented with $10 \%$ fetal bovine serum (FBS, Filtron, Brooklyn, Australia), $100 \mathrm{U} / \mathrm{ml}$ of penicillin and $100 \mu \mathrm{g} / \mathrm{ml}$ of streptomycin (Invitrogen) in a humidified atmosphere of $5 \% \mathrm{CO}_{2}$ at $37^{\circ} \mathrm{C}$.

\section{Cell growth assays of dental epithelial and mesenchymal cells treated with $T \beta 10$ using siRNA in cell culture}

T $\beta 10$-siRNA (final conc. $124 \mathrm{nM}$ ) was simultaneously transfected into $\mathrm{mDP}$ and $\mathrm{mDE} 6$ cells using hemagglutinating virus of Japan (HVJ)-liposomes (GenomOne, Ishihara Sangyo Kaisha, Osaka, Japan) when the cells were seeded in triplicate onto $3 \times 10^{5} \mathrm{cells} /$ well in 6-well plates. The HVJ-liposome complex was prepared according to the manufacturer's instructions.

At 24 and $48 \mathrm{~h}$ after treatment with siRNA, the numbers of cells in four different microscopic fields of each well were counted. The average cell number was calculated in triplicate. At least three independent experiments were performed in triplicate.

\section{Statistical analysis}

All experiments were independently repeated at least three times. Oneway ANOVA with the Tukey-Kramer comparison test or Student's $t$-test was used to determine the presence of significant differences in the real-time PCR data, immunostaining-positive ratios and cell growth values. A $p$-value $(p<0.05$ or $p<0.01)$ was considered to indicate statistically significant differences. Significant differences in the numbers of explants were assessed using the chi-square test for independence.

\section{Acknowledgements}

This work was supported in part by Grant-in-Aid from the Ministry of Education, Culture, Sports, Science and Technology of Japan, Nos. 23659859 (to T. K.) and 23792106 (H. W.).

\section{References}

AKHTER M, KOBAYASHII, KIYOSHIMAT, MATSUOK, YAMAZAH, WADAH, HONDA JY, MING X, SAKAI H (2005). Possible functional involvement of thymosin beta 4 in developing tooth germ of mouse lower first molar. Histochem Cell Bio/124:207-213.

BOCK-MARQUETTE I, SAXENAA, WHITE MD, DIMAIO JM, SRIVASTAVAD (2004) Thymosin beta 4 activates integrin-linked kinase and promotes cardiac cell migration, survival and cardiac repair. Nature 432: 466-472.

BYERS MR, SCHATTEMAN GC, BOTHWELL M (1990). Multiple functions for NGF receptor in developing, aging and injured rat teeth are suggested by epithelial, mesenchymal and neural immunoreactivity. Development 109: 461-471.

CARPINTERO P, FRANCO DEL AMO F, ANADÓN R, GÓMEZ-MÁRQUEZ J (1996). Thymosin beta $10 \mathrm{mRNA}$ expression during early postimplantation mouse development. FEBS lett 394: 103-106.

CHEN J, LAN Y, BAEK JA, GAO Y, JIANG R (2009). Wnt/beta-catenin signaling plays an essential role in activation of odontogenic mesenchyme during early tooth development. Dev Biol 334: 174-185.

COBOURNE MT, SHARPE PT (2003). Tooth and jaw: molecular mechanisms of patterning in the first branchial arch. Arch Oral Biol 48: 1-14.

FANNID, GEROSAC, NEMOLATOS, LOCCIA, MARINELLIV, CABRAST, MESSANA I, FANOS V, CASTAGNOLA M, FAA G (2011). Thymosin beta 10 expression in developing human salivary glands. Early Hum Dev 87: 779-783.

GEROSA C, FANNI D, NEMOLATO S, LOCCI A, MARINELLI V, CABRAS T, MESSANA I, CASTAGNOLA M, MONGA G, FANOS V, FAA G (2010). Thymosin beta-10 expression in developing human kidney. J Matern Fetal Neonatal Med Suppl 3: 125-128.

HALL AK (1991). Developmental regulation of thymosin beta 10 mRNA in the human brain. Brain Res Mol Brain Res 9: 175-177.

KIM YC, KIM BG, LEE JH (2012). Thymosin $\beta 10$ expression driven by the human TERT promoter induces ovarian cancer-specific apoptosis through ROS production. PLoS One 7: e35399.

KOBAYASHI I, KIYOSHIMA T, WADA H, MATSUO K, NONAKA K, HONDA JY, KOYANO K, SAKAI H (2006). Type II/III Runx2/Cbfa1 is required for tooth germ development. Bone 38: 836-844.

LEE SH, SON MJ, OH SH, RHO SB, PARK K, KIM YJ, PARK MS, LEE JH (2005), Thymosin beta10 inhibits angiogenesis and tumor growth by interfering with Ras function. Cancer Res 65: 137-148.

LIN SC, MORRISON-BOGORAD M (1990). Developmental expression of mRNAs encoding thymosins beta 4 and beta 10 in rat brain and other tissues. $J \mathrm{Mol}$ Neurosci 2: 35-44.

MINA M (2001). Regulation of mandibular growth and morphogenesis. Crit Rev Oral Biol Med 12: 276-300.

MU H, OHASHI R, YANG H, WANG X, LI M, LIN P, YAO Q, CHEN C (2006). Thymosin beta10 inhibits cell migration and capillary-like tube formation of human coronary artery endothelial cells. Cell Motil Cytoskeleton 63: 222-230.

NAHER L, KIYOSHIMA T, KOBAYASHI I, WADA H, NAGATA K, FUJIWARA H, OOKUMA YF, OZEKI S, NAKAMURA S, SAKAI H (2012). STAT3 signal transduction 
through interleukin-22 in oral squamous cell carcinoma. Int JOncol41: 1577-1586. OOKUMA YF, KIYOSHIMA T, KOBAYASHI I, NAGATA K, WADA H, FUJIWARA H, YAMAZA H, NONAKA K, SAKAI H (2013). Multiple functional involvement of Thymosin beta-4 in tooth germ development. Histochem Cell Biol 139: 355-370.

PHILP D, GOLDSTEIN AL, KLEINMAN HK (2004). Thymosin beta4 promotes angiogenesis, wound healing, and hair follicle development. Mech Ageing Dev 125: 113-115.

PISPA J, MIKKOLA ML, MUSTONEN T, THESLEFF I (2003). Ectodysplasin, Edar and TNFRSF19 are expressed in complementary and overlapping patterns during mouse embryogenesis. Gene Expr Patterns 3: 675-679

SANTELLI G, BARTOLI PC, GIULIANO A, PORCELLINI A, MINEO A, BARONE MV, BUSIELLO I, TRAPASSO F, CALIFANO D, FUSCO A (2002). Thymosin beta-10 protein synthesis suppression reduces the growth of human thyroid carcinoma cells in semisolid medium. Thyroid 12: 765-772.

TAKAHASHI KF, KIYOSHIMA T, KOBAYASHI I, XIE M, YAMAZA H, FUJIWARA H, OOKUMA Y, NAGATA K, WADA H, SAKAI T, TERADA Y, SAKAI H (2010). Protogenin, a new member of the immunoglobulin superfamily, is implicated in the development of the mouse lower first molar. BMC Dev Biol 10: 115

THESLEFF, I (2003). Epithelial-mesenchymal signalling regulating tooth morphogenesis. J Cell Sci 116: 1647-1648.

TSUBAKIMOTO T, KOSAKA K, SAITO M, TERANAKA T (2007). Immortalization of dental papilla cells differentiating into odontoblast in vitro. Japan J Conserv Dent 50: 292-301.

WANG WS, CHEN PM, HSIAO HL, JU SY, SU Y (2003). Overexpression of the thymosin beta-4 gene is associated with malignant progression of SW480 colon cancer cells. Oncogene 22: 3297-3306.

XIE M, KOBAYASHII, KIYOSHIMAT, YAMAZAH, HONDAJY, TAKAHASHI K, ENOK $\mathrm{N}$, AKAMINE A, SAKAI H (2007). Functional implication of nucleolin in the mouse first molar development. J Biol Chem 282: 23275-23283.

YAMAZA H, MATSUO K, KIYOSHIMA T, SHIGEMURA N, KOBAYASHI I, WADA H, AKAMIME A, SAKAI H (2001). Detection of differentially expressed genes in the early developmental stage of the mouse mandible. Int J Dev Biol 45: 675-680.

YOSHIZAKI K, YAMAMOTO S, YAMADA A, YUASA K, IWAMOTO T, FUKUMOTO E, HARADA H, SAITO M, NAKASIMA A, NONAKA K, YAMADA Y, FUKUMOTO $S$ (2008). Neurotrophic factor neurotrophin-4 regulates ameloblastin expression via full-length TrkB. J Biol Chem 283: 3385-3391.

YUFX, LIN SC, MORRISON-BOGORAD M, ATKINSON MA, YIN HL(1993). Thymosin beta 10 and thymosin beta 4 are both actin monomer sequestering proteins. $J$ Biol Chem 268: 502-509.

ZHAOY, QIU F, XU S, YU L, FU G (2011). Thymosin $\beta 4$ activates integrin-linked kinase and decreases endothelial progenitor cells apoptosis under serum deprivation. $J$ Cell Physiol 226: 2798-2806. 


\section{Further Related Reading, published previously in the Int. J. Dev. Biol.}

Molecular signaling at the fusion stage of the mouse mandibular arch: involvement of insulin-like growth factor family Kazuya Fujita, Yuji Taya, Yoshihito Shimazu, Takaaki Aoba and Yuuichi Soeno

Int. J. Dev. Biol. (2013) 57: 399-406

http://dx.doi.org/10.1387/ijdb.120110ys

The zebrafish sf3b1b460 mutant reveals differential requirements for the sf3b1 pre-mRNA processing gene during neural crest development

Min An and Paul D. Henion

Int. J. Dev. Biol. (2012) 56: 223-237

http://dx.doi.org/10.1387/ijdb.113383ma

A novel role for Glucocorticoid-Induced TNF Receptor Ligand (Gitrl) in early embryonic zebrafish development Lynn D. Poulton, Kathleen F. Nolan, Corina Anastasaki, Herman Waldmann and E. Elizabeth Patton

Int. J. Dev. Biol. (2010) 54: 815-825

http://dx.doi.org/10.1387/ijdb.082841lp

Over-expression of thymosin beta4 promotes abnormal tooth development and stimulation of hair growth

Hee-Jae Cha, Deborah Philp, Soo-Hyun Lee, Hye-Sung Moon, Hynda K. Kleinman and Takashi Nakamura

Int. J. Dev. Biol. (2010) 54: 135-140

http://dx.doi.org/10.1387/ijdb.082735hc

Detection of differentially expressed genes in the early developmental stage of the mouse mandible

H Yamaza, KMatsuo, T Kiyoshima, N Shigemura, I Kobayashi, HWada, AAkamime and H Sakai Int. J. Dev. Biol. (2001) 45: 675-680

http://www.intjdevbiol.com/web/paper/11461004

GDNF and its receptors in the regulation of the ureteric branching

$\mathrm{H}$ Sariola and M Saarma

Int. J. Dev. Biol. (1999) 43: 413-418

http://www.intjdevbiol.com/web/paper/10535317

5 yr ISI Impact Factor $(2011)=2.959$
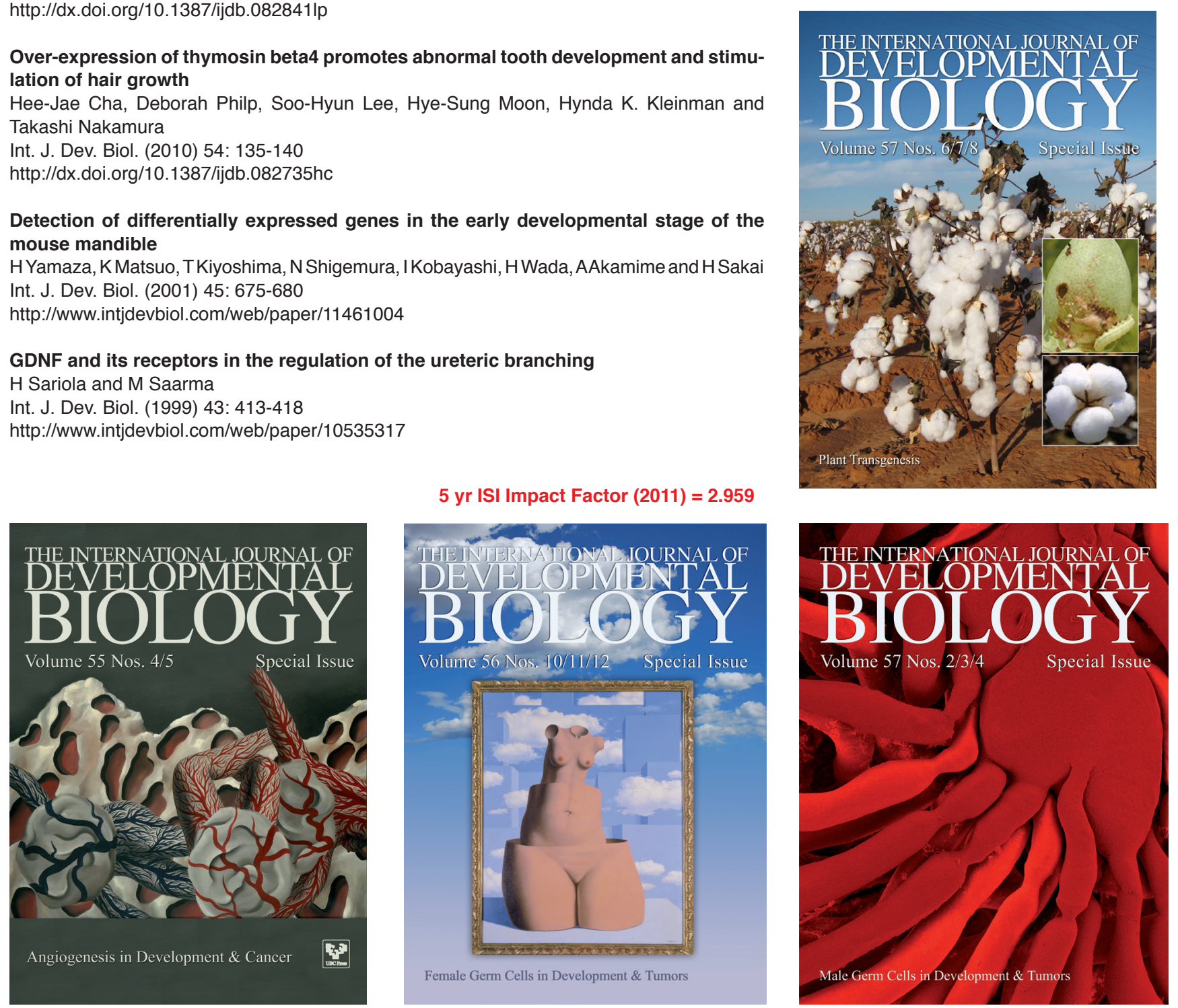